\title{
The alumni narrative of the connection between university skills and knowledge, and industry: An 'outside-in' understanding
}

\author{
David Fleischman ${ }^{1}$, Peter English ${ }^{2}$ \\ ${ }^{1}$ Business School, University of the Sunshine Coast, Australia, ${ }^{2}$ School of Communication \\ and Creative Industries, University of the Sunshine Coast, Australia
}

\begin{abstract}
This study takes an 'outside-in' approach by exploring the narratives of university alumni working in industry. The aim of the study is to understand how engaging with industry alumni supports and informs graduate skills and knowledge needed for future employability, and university career/future focused curriculum design. To achieve the aim, the study adopted an Appreciative Inquiry approach to guide a series of $n=8$ depth interviews recorded in a digital video format. This approach provided alumni with a platform to construct their unique professional narratives in a manner that was relatable and engaging to students, and that universities could use as an educational tool. Data from the interviews resulted in three main themes: 1) the necessity of soft-skills and work experience, 2) the importance of resilience, and 3) the willingness to constantly learn. Theoretically, the findings contribute externally validated support and extension of important and desirable graduate attributes, providing evidence for informing and extending career/future focused curriculum design. Practically, the findings provide students and universities with professional confirmation and foresight of the skills and knowledge needed to transition and navigate the professional workforce, along with an educational tool to implement into curriculum.
\end{abstract}

Keywords: Employability, alumni, Appreciative Inquiry, graduate skills, industry, curriculum 


\section{Introduction}

Higher Education (HE) comprises a key industry in economies around the world. In Australia, the context of this study, HE is a \$32.8 billion industry (IBISWorld 2018). Universities are facing increased pressure to grow their economic footprint (Uncles 2018). This pressure has resulted in increased competition among universities to differentiate themselves to potential student-customers and demonstrate their impact to public stakeholders (Uncles 2018). Enhancing graduate employability is one-way universities are responding to student and public needs, and government metrics. Formal curriculum design incorporating 'real world', practice-based experiences via practicum placements, work integrated learning (WIL) and internships programs, along with extra-curricular opportunities (e.g. mentor programs, ambassador roles), are now commonplace throughout degree programs. It is through these experiences, alongside course work, where students are thought to develop employability skills and knowledge.

While the body of work on employability is burgeoning, few studies have focused on the impact of engaging alumni to better understand employability. Guided by components of Bridgstock’s (2017) employability framework, this study uses Appreciative Inquiry (AI) to take an 'outside-in' approach to engage with the professional narrative of industry alumni. This provides alumni with the opportunity to communicate stories illustrating the value of the skills, knowledge and attributes developed during and after their university degree and into their professional experience. In doing so, the channel of communication regarding employability is re-routed from the institution expressing the importance of graduate skills, attributes and knowledge, to relatable, credible industry alumni confirming their importance via lived professional experiences.

\section{Background Literature}

The positive impact from engaging industry in curriculum design is well-known (Plewa et al., 2015). Multilevel analyses show institutions' connections with professional organizations positively affect graduate employment (Akkerman \& Torenvlied, 2013). These connections may emerge from several initiatives such as WIL, internship programs and other work experiences, leading to skill and knowledge development essential for future employment.

For instance, WIL and internship curriculum-based programs have been well documented in helping students develop clear expectations of industry work, soft-skill development, networking and building students' general confidence (Elijido \& Kloot, 2015; Drewery et al., 2016; Jackson, 2017). Along with studying specific outcomes of curriculum-based experiences (i.e. WIL, internships), other research focusing on completing HE degrees and participating in extra-curricular initiatives also demonstrates similar skills and knowledge outcomes contributing to employability (see Andrews \& Higson, 2014). Initiatives such as 
student ambassador and mentor programs have been shown to enhance leadership, communication, teamwork, open-mindedness, self-confidence, networking, industry insight, and help facilitate easier transitions into professional work (Smith-Ruig, 2014; Gannon et al., 2018). Other work suggests students completing university degree programs helped students develop stronger interpersonal, communication and cooperative teamwork skills necessary for employability (Hartley et al., 2018). Existing work provides consistent evidence on the skills and knowledge that contribute to employability as supported by specific curriculum and extra-curricular initiatives and general HE degree programs.

While some existing work incorporates external industry perspectives, a higher proportion of the work is from the student viewpoint, indicating an opportunity to advance the industry perspective. Specifically, little research, focuses on sharing the narratives and experiences of industry alumni to engage with students from the same institution. Some exceptions include Barnard and Rensleigh (2008), who examined information sharing among alumni, and Warren et al. (2016), who explored the benefits of interviewing alumni. Indeed, engaging with alumni has the potential to create a stronger, more tangible understanding of employability and connection to industry due to the relatability of studying at the same institution and that alumni represent the notion of success after graduation (Gallo, 2018). This existing work reflects the opportunity of engaging with alumni as mechanism to broaden the scope of understanding employability to include the development of social capital and individual behaviours as suggested by Clarke (2018).

Focusing on the latter opportunity, this study is guided by Bridgstock's (2017) Graduate Employability 2.0 framework. Bridgstock (2017) developed a framework supporting graduate employability through connectedness learning. Bridgstock (2017) suggests external relationships and professional networks are key, serving to maximise graduate employability and enhance the relevance of HE curriculum through better industry alignment at three connectedness learning levels: capabilities, pedagogies and strategies. Using a digital video format to explore alumni narratives of transitioning from university to industry and their continued professional advancement, this study aligns with a component from each level of Bridstock's model: growing connections; alumni engagement; and use of connectedness enabling digital tools and infrastructure. It supports the exploration of the following research question: What skills and knowledge do alumni develop during their university and industry experiences that are important for current students as they prepare to transition into the professional workforce and navigate future career paths?

\section{Method}

Given the exploratory nature of the study, a qualitative methodology using depth interviews was appropriate. The depth interviews were guided using an Appreciative Inquiry (AI) 
approach. Briefly, AI is a reflective process focused on understanding the reality of how organizational change is impacted by what currently works and is of value, what might and should be, and what future innovations may be (Hammond, 2013). AI in educational research is suggested when aiming to gain new perspectives, avoiding stereotypical answers, identifying areas of good practice and new ways forward, and capturing the voices of young people (Shuayb et al., 2009), fitting this research. Using an AI approach is also point of differentiation from existing work, adding a level of tangibility to the professional narratives of alumni, allowing current students to engage with the, "strengths, possibilities and successes” (Stavros et al., 2015, p. 97) - illustrating how their degree is preparing them for industry transition and career progression. Eight depth interviews lasting between 30 minutes and one hour were conducted at a regional university campus or via Skype. Respondents had to meet the following criteria: 1) alumni of the university, and 2) working in industry for a minimum of three years. An AI interview protocol, informed by the extant literature, was designed so respondents constructed authentic narratives. Data underwent manual thematic analysis. Common themes were identified and were grouped, enabling an understanding of emergent patterns and attributing meaning to the data (Saldana, 2015).

\section{Findings and Discussion}

The findings and discussion are organized by the themes that emerged, with the final section outlining connections to Bridgstock’s (2017) framework.

\subsection{Theme 1 - Soft-skills and work experience}

In relation to AI, soft-skills were seen of value to alumni during their university experience (Hammond, 2013). Findings demonstrate general alignment with extant literature in terms of soft-skills. All respondents reflected on experiences where they realized how much their degree helped them develop the soft-skills to prepare them for employment. People skills were one type of soft-skill mentioned consistently in respondents' narratives. As an environmental science respondent working in business said, "Some of the specific things I learned was people skills, learning how to do deal with different types of people. I guess it all comes down to how you learn from and work with different people.” Another respondent working in marketing and PR stated, "I have now come to appreciate the soft-skills that I picked up during my four years studying...those people skills... 99\% of my job is group work.” Problem solving was another skill respondents reflected upon as a business graduate mentioned, "The processes I learned in university for completing assignments I apply to everything I'm doing now...If it's applying for a new job...I research the company, do up my proposal, my CV, refine it and ask questions to others working there or in forums.” These findings indicate consistency with what has been found in the literature (e.g. Hartley et al., 2018; Smith-Ruig, 2014; Gannon et al., 2018). 
Further, a more nuanced perspective of soft-skills emerges through AI narratives. In their reflections, respondents indicated the soft-skills they learned in university are not used in silos, but together. For instance, reflecting on skills developed at university, a business degree respondent provided an example of being emotionally intelligent to communicate with people and solve problems, "It was my second week...suddenly an email was directed at me from a very senior executive, with numerous other staff copied in, with a very blunt statement saying I hadn't delivered this and where was that? So, I thought about it, discussed it with my manager and just stuck with a very factual response...that taught me a valuable lesson not to get emotive on email and to talk with my team.” These findings demonstrate soft-skills learned at university are not always apparent until students gain professional experience and reflect on their narratives to appreciate the value of the skills developed while studying.

Work experience was valuable for alumni during their university degree, something that all universities should encourage and make essential for transitioning into future professional environments. This aligns well with what AI aims to understand as would should be (Hammond, 2013). As a marketing degree respondent expressed, "The thing I wish I was told as a student is the importance of work experience. I think every student should have this opportunity during their degree... That's the advice I would give, get in there and work with businesses to find out what they need.” An arts and business degree respondent strongly advocated for volunteering to gain experience, stating, “An opportunity came up to volunteer in South Africa during a study break...it was so far beyond anything that I had done in terms of traditional work experience behind a computer...it made all the difference to my professional skills at work because I was able to write about what was involved with it because of having experienced it." While there was mention of structured, curriculum-based WIL and placement experiences within the literature (e.g. Elijido \& Kloot, 2015; Drewery et al., 2016; Jackson, 2017), findings indicated any type of work experience, including volunteering, was key in preparing to transition to professional work.

\subsection{Theme 2 - Resilience}

More of a developed trait than a skill, resilience was mentioned by all respondents as important to transitioning into industry, and a trait all students should develop. An occupational therapy respondent stated, "You kind of hand in your last assignment and wonder what do I do now?...Where do I fit and what can I do with my degree...it's hard to get the exact job you want...but you just got to pull up your socks, and dig, and take the job that will allow you to get experience.” A business degree respondent noted the importance of resilience when going through the corporate interview process, "It took 3-5 interviews over 3-4 months, with different companies. Sometimes I would get to the very end and not get it, but I continued to persevere by asking questions.” 
These findings illustrate the importance of resilience as an element of employability, particularly as students transition from studying into professional work. In relation to AI, students should be aware that resilience building experiences are part of the professional transition and career progression. Universities should consider how they can understand and contribute to developing resilience in students preparing them for the future work world. In some contrast, the findings may also imply resilience is difficult to learn in university. Instead, it is built through experiences, albeit these may start during university. Nevertheless, there is an opportunity for future research on resilience in HE, as most studies are based in the HRM context.

\subsection{Theme 3 - Desire to constantly learn, adapt and evolve}

Once respondents had successfully transitioned into professional work from university, all noted the salience to constantly learn, adapt and evolve to develop a broad knowledge base.

A journalism degree respondent noted, “My job now didn’t exist when I was at uni...you have to be multi-skilled now because of fast paced change in industry. There was a lot of work outside of hours learning....anything you can think to gain experience.” Similarly, an environmental science respondent describes his account of starting an environmental consulting business, "The business side of things was a total different kettle of fish I had to learn about. I went back to study and did a small business certificate four...it was continual development for me...that's what it's all about.” Through AI, these findings highlight not only the future need to constantly learn, adapt and evolve, but notable points regarding how this can be achieved. It suggests students need to prepare for future work (which may not yet exist!) and career progression. Students should also be expected to develop new skills in their own time, either via additional study or volunteering to take on opportunities outside of their designated job role. Similar to developing resilience, university degrees equip students with the tools to learn, but the need to continually learn, adapt and evolve may not always be realized until students become professionals. As such, it is suggested universities consider drawing on broader employability dimensions to complement the current human capital approach underpinned by tangible skill development and embedded curriculum elements (i.e. WIL and internships) (Clarke, 2018).

\subsection{Connection to Bridgstock's (2017) framework}

The findings in this study highlight the importance of students developing soft-skills and work experience, resilience, and the desire to learn constantly. These findings can be used to support, inform and extend graduate skill/attributes and career/future focused curriculum. More specifically, in terms of Bridgstock's (2017) framework, they reflect the value of growing connections, through networking and professional networks, and including greater alumni engagement through degree programs, such as guest lectures, mentoring programs 
and online via digital content. This can help to avoid the "I wish I knew" moments experienced in employment as outlined by respondents. Further, the dissemination of the findings, via digital clips available online, is aligned with the importance of connectedness enabling digital tools and creates opportunities for consistent interaction as suggested by Bennet and Kane (2009).

\section{Limitations, future research and conclusions}

This study adopted an Appreciative Inquiry approach to guide a series of depth interviews exploring the narratives of university alumni working in industry. Theoretically, the findings contribute externally validated support and extension of important and desirable graduate attributes, providing evidence for informing career/future focused curriculum design. The findings also offer evidence supporting components of Bridgstock's (2017) theoretical framework. Practically, the findings provide students and universities with professional confirmation and foresight of the skills, attributes and knowledge needed to transition and navigate the professional workforce, and an online educational tool to implement into curriculum. However, there are limitations that require acknowledgement. Importantly, the findings are based on depth interviews with eight alumni at one regional university, limiting their generalizability. This highlights scope for further research in this alumni-reflection space in universities of other sizes, locations, and using quantitative methods.

\section{References}

Akkerman, A., \& Torenvlied, R. (2013). Public management and network specificity: Effects of colleges' ties with professional organizations on graduates' labour market success and satisfaction. Public Management Review, 15(4), 522-540.

Andrews, J., \& Higson, H. (2014). Is Bologna working? Employer and graduate reflections of the quality, value and relevance of business and management education in four European Union countries. Higher Education Quarterly, 68(3), 267-287.

Barnard, Z., \& Rensleigh, C. (2008). Investigating online community portals for enhanced alumni networking. The Electronic Library, 26(4),433-445.

Bennett, R., \& Kane, S. (2009). Employer engagement practices of UK business schools and departments: An empirical investigation. Journal of Vocational Education \& Training, 61(4), 495-516.

Bridgstock, R. (2017). The university and the knowledge network: A new educational model for twenty-first century learning and employability. In M. Tomlinson \& L. Holmes (Eds.), Graduate Employability in Context Theory, Research and Debate (pp. 339-358). London, UK: Macmillan.

Clarke, M. (2018). Rethinking graduate employability: The role of capital, individual attributes and context. Studies in Higher Education, 43(11), 1923-1937. 
Drewery, D., Nevison, C., \& Pretti, T.J. (2016). The influence of cooperative education and reflection upon previous work experiences on university graduates' vocational selfconcept. Education + Training, 58(2), 179-192.

Elijido-Ten, E., \& Kloot, L. (2015). Experiential learning in accounting work-integrated learning: A three-way partnership. Education + Training, 57(2), 204-218.

Gallo, M. L. (2018). How are graduates and alumni featured in university strategic plans? Lessons from Ireland. Perspectives: Policy and Practice in Higher Education, 22(3) 9297.

Gannon, S., Tracey, D., \& Ullman, J. (2018). Bolstering graduates’ success through working as student ambassadors in university widening participation programs. Higher Education Research \& Development, 37(4), 715-729.

Hammond, S. A. (2013). The thin book of appreciative inquiry. Thin Book Publishing.

Hartley, P., Routon, P. W., \& Torres, L. (2018). The skills marketing majors believe they acquire: Evidence from a national survey. Journal of Marketing Education. In press.

IBISWorld (2018). University and Other Higher Education - Australia Market Research Report. Retried from: <https://www.ibisworld.com.au/industry-trends/marketresearchreports/education-training/university-other-higher-education.html>.

Jackson, D. (2017). Developing pre-professional identity in undergraduates through workintegrated learning. Higher Education, 74(5), 833-853

Plewa, C., Galán-Muros, V. and Davey, T. (2015). 'Engaging business in curriculum design and delivery: a higher education institution perspective', Higher Education, 70(1), 35-53. Saldana, J. (2015). The coding manual for qualitative researchers. Sage.

Smith-Ruig, T. (2014). Exploring the links between mentoring and work-integrated learning. Higher Education Research \& Development, 33(4), 769-782.

Shuayb, M., Sharp, C., Judkins, M., \& Hetherington, M. (2009). Using appreciative inquiry in educational research: Possibilities and limitations. National Foundation for Educational Research. Retrieved from: $<$ https://www.nfer.ac.uk/publications/AEN01/AEN01.pdf>.

Stavros, J.M., Godwin, L.N., \& Cooperrider, D.L. (2015). Appreciative inquiry: Organization development and the strengths revolution. Practicing organization development: Leading transformation and change, 96-116.

Warren, M.M., Drapela, D.J., Bredimus, K.N., Flores, J.Y., Henderson, C.I., Wright, T.,

Lanning, K.A. and Dryden, I.R., (2016). Exploring Alumni Stories Through Qualitative Research. Retrieved from: $<$ http://digitalcommons.wou.edu/cgi/viewcontent.cgi?article=1078\&context=aes $>$.

Uncles, M.D. (2018). Directions in higher education: A marketing perspective. Australasian Marketing Journal, 26(2), 187-193. 